\title{
Levantamento preliminar dos morcegos do Parque Nacional de Ubajara (Mammalia, Chiroptera), Ceará, Brasil
}

\author{
Shirley Seixas Pereira da Silva ${ }^{1}$ \\ Patrícia Gonçalves Guedes ${ }^{2}$ \\ Adriano Lúcio Peracchi ${ }^{3}$
}

\begin{abstract}
Preliminary survey of the Bats from Ubajara National Park (Mammalia-Chiroptera), Ceará, Brazil. A preliminary survey of bats species from the Ubajara National Park is presented. One hundred sixty two bats from 14 species were collected. Comments about reproduction of the captured species are included. KEY WORDS. Chiroptera, bats, reproduction, Ceará, Brazil
\end{abstract}

O Parque Nacional de Ubajara (PNU), situado na Serra da Ibiapaba, noroeste do Estado do Ceará, é o menor Parque Nacional do Brasil com apenas 563 hectares, criado através do Decreto Federal número 45954 de 30/04/1959.

No ano de 1981 foi realizado o Plano de Manejo dessa Unidade de Conservação, onde foi registrada apenas uma espécie de morcego, Furipterus horrens (F. Cuvier, 1828) (IBDF 1981), cuja presença havia sido anteriormente citada por UIEDA (1980) ao realizar observações na Gruta de Ubajara e Gruta de Araticum.

Pouco se sabe sobre a quiropterofauna da região da Chapada da Ibiapaba. Além do registro de $F$. horrens existem apenas os registros de mais três espécies de morcegos, a saber: Artibeus lituratus (Olfers, 1818), Carollia perspicillata (Linnaeus, 1758) e Plathyrrinus lineatus (E. Geoffroyi, 1810) (THOMAS 1910; PICININI 1971, 1974).

PAIVA (1973) estudou a fauna de mamíferos do Estado do Ceará, incluindo informações sobre esta Serra, porém suas observações não abrangeram morcegos e marsupiais. MARES et al. (1981) realizaram um levantamento da fauna de mamíferos da região nordeste, porém suas observações não incluíram a região da Serra da Ibiapaba.

Este trabalho tem por objetivo apresentar os resultados de um levantamento das espécies de quirópteros que ocorrem na área do PNU, para fins de "Revisão do Plano de Manejo", onde são acrescentadas 13 espécies à lista oficial do IBAMA, fornecendo dados preliminares sobre os hábitos alimentares e a reprodução de algumas das espécies registradas.

1) Fundaçäo Instituto Estadual de Florestas. Avenida 13 de Maio $33,26^{\circ}$ andar, Centro, 20031-000 Rio de Janeiro, Rio de Janeiro, Brasil. E-mail: batshirl@ig.com.br

2) Departamento de Vertebrados, Museu Nacional, Universidade Federal do Rio de Janeiro. Quinta da Boa Vista, São Cristóvão, 20940-040 Rio de Janeiro, Rio de Janeiro, Brasil. E-mail: pgguedes@acd.ufrj.br

3) Instituto de Biologia, Universidade Federal Rural do Rio de Janeiro. Caixa Postal 74503 , 23851-970 Seropédica, Rio de Janeiro, Brasil. 


\section{MATERIAL E MÉTODOS}

\section{Área de Estudo}

O Parque Nacional de Ubajara está localizado a $40^{\circ} 52^{\prime}-40^{\circ} 55^{\prime} \mathrm{W}$ e $3^{\circ} 48^{\prime}$ $3^{\circ} 50$ 'S. Em seu relevo acidentado localizam-se diversas cavernas calcáreas, que servem de abrigo para uma grande variedade de animais.

As coletas foram conduzidas no PNU no período de dezembro de 1998 a fevereiro de 1999, nos seguintes pontos: Centro de Visitantes; nas Grutas de Ubajara, do Morcego Branco e do "Tião"; Morro do Pendurado; Horto (sede da Administração do Parque), e em uma localidade denominada "Murimbeca" (distrito de Ubajara).

Para a captura dos espécimes foram utilizadas 05 (cinco) redes do tipo mist-nets $(9,0 \times 2,5 \mathrm{~m})$ em trilhas no interior da mata, na entrada das grutas e no entorno do alojamento de pesquisadores do Horto (visando à coleta de exemplares que habitam esses locais), no período das 18 (correspondente ao início do anoitecer) às 22 horas, perfazendo um total de 91 horas de esforço. $\mathrm{O}$ material mumificado (esqueletos) foi coletado nas grutas durante visitas nos períodos da manhã e tarde. Ao longo do trabalho foram coletados 162 exemplares de quirópteros, pertencentes a três famílias e 14 espécies. Todos os animais que se encontravam em período reprodutivo (fêmeas grávidas, fêmeas lactantes e machos escrotados) foram liberados ao final de cada noite de coleta, após anotação de dados pertinentes.

Alguns exemplares foram sacrificados visando a organização de uma coleção representativa da região. Estes foram conservados em álcool $70 \%$ ou sob a forma de pele cheia (taxidermizados) e encontram-se incorporados às coleções da Universidade Federal do Ceará (UFC) e da Organização Não-Governamental Instituto Cearense de Ciências Naturais (ICCN).

Para obtenção de dados sobre os hábitos alimentares, os animais foram mantidos em sacos de pano, os quais, após a soltura, foram examinados para obtenção das fezes e identificação de seu conteúdo.

$\mathrm{Na}$ citação das espécies listadas abaixo foi utilizada a nomenclatura proposta por KOOPMAN (1993).

\section{RESULTADOS}

\section{Phyllostomidae}

Phyllostominae

Phyllostomus Lacépède, 1799

\section{Phyllostomus discolor Wagner, 1843}

Foram capturados nove exemplares, dos quais sete com rede armada no interior do Horto. Os outros dois exemplares foram obtidos através da coleta dos esqueletos completos mumificados no interior da Gruta do Tião. No mês de dezembro de 1998 foi coletada uma fêmea lactante, um macho escrotado.

Material examinado. Seis fêmeas (08-XII-98); dois esqueletos mumificados e completos (17-XII-98).

Phyllostomus hastatus (Pallas, 1767)

Foram coletados três esqueletos mumificados e completos no interior da Gruta do Tião em 18-XII-98. 


\section{Glossophaginae}

Glossophaga E. Geoffroy, 1818

Glossophaga soricina (Pallas, 1766)

Três exemplares dessa espécie foram obtidos. Um macho e uma fêmea foram capturados nas proximidades do Centro de Visitantes do PNU e um esqueleto completo mumificado foi coletado no Morro do Pendurado.

Material examinado. Uma fêmea (23-I-99); um macho (27-I-99); esqueleto completo (29-I-99).

Lonchophyllinae

Lonchophylla Thomas, 1903

\section{Lonchophylla sp.}

Foi colecionado apenas um esqueleto mumificado obtido no Morro do Pendurado, em 29-I-99.

\section{Carollinae}

\section{Carollia Gray, 1838}

\section{Carollia perspicillata (Linnaeus, 1758)}

Foram colecionados 47 exemplares dessa espécie, a mais freqüente na região. Em dezembro de 1998 foram coletadas vinte fềmeas, uma das quais lactante (colecionada no Horto) e uma jovem (coletada na Gruta do Morcego Branco). Dos quinze machos coletados no mesmo período, apenas um estava escrotado (proveniente da Gruta do Morcego Branco); também foi coletado um exemplar macho na grande colônia existente na Gruta de Ubajara. No mês de janeiro de 1999, foram coletados sete exemplares no Centro de Visitantes: das quatro fêmeas, três eram lactantes; dos três machos, dois estavam escrotados. Em fevereiro de 1999 foram coletados mais dois machos no Centro de Visitantes e uma fêmea no Horto.

Material examinado. Um macho e duas fêmeas (08-XII-98); um macho (11-XII-98); treze machos e dezoito fêmeas (12 e 13-XII-98); quatro fêmeas e três machos (23-I-99); um macho (03-II-99); uma fêmea (08-II-99).

\section{Stenodermatinae}

\section{Sturnira Gray, 1842}

\section{Sturnira lilium (E. Geoffroy, 1810)}

Este morcego de hábito frugívoro foi coletado apenas em locais onde a vegetação apresentava-se mais abundante (Mata Úmida) e com uma maior oferta de alimento, como é o caso do Horto e do Centro de Visitantes. Foi colecionado um total de 23 exemplares. Em dezembro de 1998, as redes foram estendidas embaixo de exemplares de Cecropia spp. onde obteve-se 22 exemplares, 14 machos (dos quais 12 estavam escrotados e um monorquídeo) e oito fêmeas (sendo que seis destas estavam lactantes). O conteúdo fecal dos exemplares coletados revelou semente desses vegetais. Em fevereiro de 1999 foi coletado apenas um macho.

Material examinado. Quatorze machos e oito fêmeas (08-XII-98); um macho (03-II-99). 


\section{Platyrrhinus Saussure, 1860}

Platyrrhinus lineatus (E. Geoffroy, 1810)

Assim como Sturnira lilium, esta espécie foi colecionada sempre em regiões de Mata Úmida (Horto, Centro de Visitantes e Murimbeca). No ano de 1999 foram coletados quatro exemplares; em janeiro foram capturados uma fêmea lactante e um macho e em fevereiro uma fêmea e um macho.

Material examinado. Uma fêmea e um macho (28-I-99); uma fêmea (03-II99); um macho (04-II-99).

Chiroderma Peters, 1860

Chiroderma villosum Peters, 1860

Apenas um exemplar dessa espécie foi capturado no mês de janeiro de 1999, no Centro de Visitantes do PNU.

Material examinado. Um macho (27-I-99).

Artibeus Leach, 1821

Artibeus planirostris (Spix, 1823)

Seis fêmeas foram colecionadas, sendo que deste total duas estavam grávidas em dezembro de 1998 e uma outra em janeiro de 1999. A coleta dessa espécie sempre esteve associada à de outras espécies frugívoras, como Sturnira lilium, Carollia perspicillata, Phyllostomus discolor e Chiroderma villosum. Durante o período de estudo não foram coletados machos dessa espécie.

Material examinado. Cinco fêmeas (08-XII-98); uma fêmea (27-I-99).

Artibeus lituratus (Olfers, 1818)

Apesar de ser uma espécie bastante colecionada e muito comum em diversas regiões do território brasileiro, foi coletado apenas um macho escrotado durante todo o período de estudo, na área do Horto.

Material examinado. Um macho (08-XII-98).

\section{Artibeus obscurus Schinz, 1821}

Esta espécie foi coletada apenas em regiões de vegetação abundante (Mata Úmida). Em dezembro de 1998 coletou-se apenas uma fềmea grávida. No ano de 1999 foram coletadas duas fêmeas grávidas; em janeiro, uma fêmea lactante e um macho escrotado; e em fevereiro seis fêmeas (das quais uma lactante) e um macho foram coletados. Durante o período de estudo verificou-se que alguns exemplares apresentavam restos de polpa de frutos na boca e nas fezes, porém não foi possível a identificação da espécie vegetal.

Material examinado. Uma fêmea (08-XII-98); duas fêmeas (23-I-99); uma fêmea e um macho (28-I-99); três fêmeas (03-II-99); uma fêmea (04-II-99); duas fêmeas e um macho (08-II-99).

\section{Desmodontinae}

Desmodus Wied-Neuwied, 1826

Desmodus rotundus (E. Geoffroy, 1810)

Todos os dez exemplares dessa espécie hematófaga, foram obtidos no 
interior da Gruta do Morcego Branco. Foram observados também dois exemplares voando na "Sala das Cortinas", no interior da Gruta de Ubajara. Na "Gruta do Tião" foram coletados vários crânios isolados dessa espécie. Em dezembro foram colecionadas cinco fêmeas, sendo que duas estavam grávidas. Dos cinco machos obtidos dois estavam escrotados neste mesmo período.

Material examinado. Cinco fềmeas e cinco machos (12 e 13-XII-98).

\section{Furipteridae}

\section{Furipterus Bonaparte, 1837}

Furipterus horrens (F. Cuvier, 1828)

Este pequeno morcego insetívoro foi à única espécie registrada no plano de manejo realizado para PNU (IBDF 1981). Foram colecionados dois exemplares desta espécie na Gruta de Ubajara. Observou-se que os individuos desta espécie formavam pequenas colônias de no máximo dez indivíduos em uma das entradas dessa Gruta. UiEDA et al. (1980) observou nesta mesma Gruta colônias com até 250 indivíduos, onde os indivíduos formavam pequenos agrupamentos de quatro a seis animais, ou grupos de até 30 morcegos, localizando-se sempre em depressões da paredes laterais, galerias e salões, não havendo contato corporal entre os grupos.

Material examinado. Um macho e uma fêmea (11-XII-98).

\section{Molossidae}

Molossus E. Geoffroy, 1805

Molossus molossus (Pallas, 1766)

Todos os 45 exemplares foram coletados no Horto. Esta espécie habita os forros e telhados das residências existentes nesta área. Dos 14 machos capturados, dois estavam escrotados. Em dezembro de 1998 foram coletados 15 exemplares; em janeiro de 1999, coletou-se 27 animais e em fevereiro coletou-se apenas uma fềmea jovem.

Material examinado. Dez machos e cinco fêmeas (09-XII-98); quatro machos e três fêmeas (30-I-99); uma fêmea (08-II-99).

\section{DISCUSSÃO}

Os dados apresentados, embora resultem de um esforço preliminar para a compreensão da diversidade de quirópteros presente no Parque Nacional de Ubajara, revelam o expressivo número de espécies encontradas nesta área, levando-se em consideração as reduzidas dimensões do Parque. Além disso, durante os trabalhos de campo observou-se que esta quiropterofauna tem sido ameaçada diretamente pelos intensos desmatamentos que ocorrem na área da Chapada, o que consiste em uma séria preocupação.

Desta maneira, esses resultados contribuem significativamente para o conhecimento da fauna de morcegos local e indicam a necessidade de estudos mais detalhados sobre a diversidade e ecologia dos quirópteros desta região, bem como seu estatus de conservação na região da Chapada da Ibiapaba, que apresenta uma peculiaridade vegetacional bastante distinta da vegetação típica de caatinga, e do Estado do Ceará de uma maneira geral. 
AGRADECIMENTOS. Ao Instituto Brasileiro do Meio Ambiente e dos Recursos Naturais Renováveis (IBAMA), pela permissão de coleta e pelo apoio logístico; ao ICCN, pelo convite para a realização deste estudo; à Profa Diva Maria Borges-Nojosa (Universidade Federal do Ceará) e aos funcionários da Cooperativa de Trabalho e Assistência ao Turismo e Prestação de Serviços Gerais (COOPTUR) pelo importante auxilio nos trabalhos de campo.

\section{REFERÊNCIAS BIBLIOGRÁFICAS}

IBDF. 1981. Plano de Manejo: Parque Nacional de Ubajara. Brasília, IBDF, 145p.

KoOPMAN, K.F. 1993. Order Chiroptera, p. 137-241. In: D.E. WILSON \& D.M. REEDER (Eds.). Mammal

Species of the World. A Taxonomic and Geographic reference. Washington, Smith. Inst. Press, $2^{\text {nd }}$ ed., XVIII $+1206 \mathrm{p}$.

Mares, M.A; M.R. Willig; K.E. Streilein \& T.E. Lacher JR. 1981. The mammals of northeastern Brazil: A preliminary assessment. Ann. Carnegie Mus. Nat. Hist. 50 (4): 81-137.

Parva, M.P. 1973. Distribuição e abundância de alguns mamiferos selvagens no Estado do Ceará. Ciência e Cultura 25 (5): 442-450.

PICININI, R.S. 1971. Estudo sistemático e bionômico dos quirópteros (Chiroptera) do Estado do Ceará.

Rev. Med. Vet. 7 (1): 39-52.

. 1974. Lista provisória dos quirópteros da coleção do Museu Paraense Emílio Goeldi

(Chiroptera). Bol. Mus. Paraense Emílio Goeldi, Zool., 77: 1-32.

Thомаs, O. 1910. On mammals from Ceará. Ann. Mag. Hist. (8) 6: 500.

Uieda, W.; I. SAzima \& A. Storti Filho. 1980. Aspectos da biologia do morcego Furipterus horrens

(Mammalia, Chiroptera, Furipteridae). Rev. Brasil. Biol. 40 (1): 59-66.

Recebido em 30.III.2000; aceito em 02.IV.2001. 